\title{
Research on wooden window nodes of optimal design
}

\author{
Jing Liu ${ }^{I}$, Yingqi $\mathrm{Chen}^{1}$, Fei Meng ${ }^{1}$, and Zongxue Chen $^{2}$ \\ ${ }^{1}$ College of Civil Engineering and Architecture, Hebei University, Baoding, Hebei, 071002, China \\ ${ }^{2}$ Hebei construction group corporation limited, Baoding, Hebei, 071052, China
}

\begin{abstract}
Mortise connection is a unique way of connection in the wood structure of ancient buildings in China. This paper takes the mortise and mortise joints of wood window frame as the object. Eight models of wooden window frames are built in ANSYS software with the parameters of tenon diameter and tenon length. The static performance of them is studied. Through simulation loading, the ultimate bearing capacity of the model under vertical and horizontal loads is obtained, and it is concluded that the Mohr strength of the dangerous point and the maximum displacement value at the contact of the mullion and mullion are linearly related to the applied load. Through the parameter analysis, such as the diameter and length of mortise and tenon joint, the optimal design of this kind of mortise and tenon joint component are carried out so as to provide the theoretical basis for its application in the actual project.
\end{abstract}

\section{Introduction}

Mortise and tenon structure is a kind of component which combines the concave and convex parts to connect the two components[1]. The protruding part is tenon, the concave part is mortise. This unique connection mode endows the wood structure with good elasticity, and each node is rigid and flexible, which makes the wood structure have good energy consumption capacity. Therefore, this kind of connection structure is widely used in ancient wood structure buildings in China, and it is still used in the design and manufacture of modern wood furniture and prefabricated wooden villa[2].

The mechanical mechanism of mortise and mortise structural connections are very complex. During the processing, the section of mortise and mortise joint will be weakened, the bearing capacity will be reduced, and it is easy to become the weak part in the structure[3]. There are more than 100 kinds of mortise and mortise structures, which can be roughly divided into face to face structure, point structure, and joint mortise and mortise structures. In this paper, it is studied that the static performance analysis of face to face mortise and tenon structure under vertical and horizontal loads.

\section{Establishment of finite element model}

In this paper, the finite element model is built in ANSYS software according to the dimension of the solid model of wooden window frame provided. Because the model is axisymmetric, in order to simplify the calculation, one half of the whole model can be built in the software. The wood window frame model are shown in Fig.1-Fig.4.

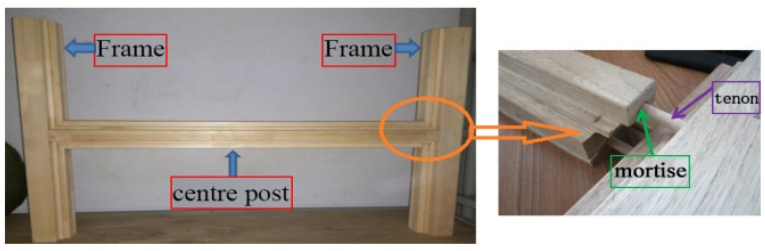

Fig.1. Entity model

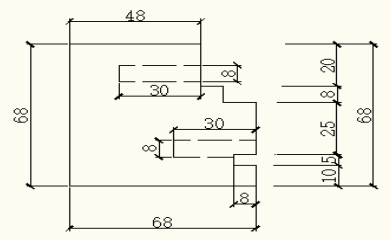

Fig.2.Sectional dimension of mullion

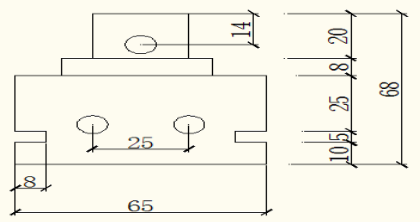

Fig.3.Cross section dimension of cross stiles

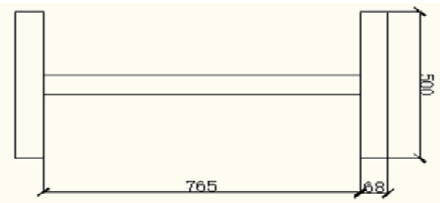

Fig.4.Dimensional drawing of solid model

In the selection of wood window frame materials, the imported wood pineapple material is selected according to the stress analysis and strength checking calculation of bucket arch joint area, with the density of $800 \mathrm{~kg} / \mathrm{m}^{3}$ and the friction coefficient of 0.2 . In the calculation, nine 
independent elastic constants are defined, which are respectively the elastic modulus $\mathrm{E}_{1}, \mathrm{E}_{2}, \mathrm{E}_{3}$, Poisson's ratio $P_{R X-Y}, P_{R X-Z}, P_{R Y-Z}$, shear modulus $G_{X}, G_{Y}, G_{Z}$ in three directions, as shown in Table 1. The compressive strength $f_{c}$, the tensile strength $f_{t}$, the shear strength $f_{v}$, the bending strength $f_{m}$ and the transverse compressive strength $\mathrm{f}_{\mathrm{c}-90}$ of the wood are defined respectively. The specific values are shown in Table 2.

Table 1 The parameters of wood mode

\begin{tabular}{|c|c|c|c|c|c|c|c|c|}
\hline \multirow{3}{*}{\multicolumn{2}{|c|}{\begin{tabular}{|c|c}
$\mathrm{E}_{1}$ & $\mathrm{E}$ \\
$12.2 \times 10^{9}$ & $12.2)$ \\
\end{tabular}}} & \multirow{3}{*}{\multicolumn{2}{|c|}{\begin{tabular}{c|c|c|c}
$E_{2}$ & $E_{3}$ & $P_{R X-1}$ \\
$2 \times 10^{9}$ & $12.2 \times 10^{9}$ & 0.1 \\
\end{tabular}}} & \multirow{3}{*}{\begin{tabular}{|c|}
$\mathrm{P}_{\mathrm{RX}-\mathrm{Z}}$ \\
0.1 \\
\end{tabular}} & \multirow{3}{*}{\begin{tabular}{|c|}
$P_{\mathrm{RY} Z}$ \\
0.1 \\
\end{tabular}} & \\
\hline & & & & & & $\mathrm{G}_{\mathrm{X}}$ & $\mathrm{G}_{\mathrm{Y}}$ & $\mathrm{G}_{\mathrm{z}}$ \\
\hline & & & & & & \multicolumn{3}{|c|}{$6.1 \times 10^{8} 6.1 \times 10^{8} 6.1 \times$} \\
\hline \multicolumn{9}{|c|}{ Table 2 Wood strength (unit: MPa) } \\
\hline & $\mathrm{f}_{\mathrm{c}}$ & $\mathrm{f}_{\mathrm{t}}$ & & $f_{v}$ & & $f_{\mathrm{m}}$ & $f_{c-9}$ & \\
\hline & 18 & 12 & & 2.8 & & 20 & 4.2 & \\
\hline
\end{tabular}

To control the diameter and length of different mortise and tenon, 8 models of mortise and tenon structures are established, and the detailed dimensions are shown in Table 3.

Table 3 The dimensions of mortise and tenon (unit: $\mathrm{mm}$ )

\begin{tabular}{|c|c|c|c|c|c|c|c|c|}
\hline $\begin{array}{c}\text { Model } \\
\text { number }\end{array}$ & D7 & D8a & D8b & D9 & D10a & D10b & D12a & D12b \\
\hline $\begin{array}{c}\text { Tenon } \\
\text { diameter }\end{array}$ & 7 & 8 & 8 & 9 & 10 & 10 & 12 & 12 \\
\hline $\begin{array}{c}\text { Tenon } \\
\text { length }\end{array}$ & 60 & 60 & 80 & 60 & 60 & 80 & 60 & 80 \\
\hline
\end{tabular}

According to the analysis of the concrete situation of wooden frame mortise and tenon structure, solid element solid45, which can simulate the actual working performance of the joint of mullion and mullion in the wooden window frame, is selected to simulate. Compared with the direct modeling method, the more general solid modeling method is used in the modeling method. During the establishment, the overall coordinate system is used for the cross mullion and mullion, and the local coordinate system is used for the round bar. In order to improve the quality of grid division, the image division method is used to make the grid division in the contact part of mullion and mullion more precise, and the grid division in other parts can be slightly rough.

In this model, the target surface is the surface of the round bar, the contact surface is the inner surface of the cross bar and the groove of the mullion that contact with the round bar, and the contact surface between the cross bar and the mullion is the target surface, and the contact surface between the cross bar and the mullion that contact with the mullion defines four contact pairs. For the analysis of contact problems, the important factor affecting the calculation accuracy and convergence is the contact stiffness[4], which needs to be selected through some relevant experience. For large-area solid contact, we can estimate the normal contact stiffness factor FNK $=1.0$; for the soft part (bending dominates), we can estimate $\mathrm{FNK}=0.01 \sim 0.1$. The normal contact stiffness factor of this model is 0.01 .

Finally, the constraints of boundary conditions are consistent with the actual situation of the model, and symmetrical constraints are applied on the middle surface of the mullion. The upper end of mullion constrains the displacement in $\mathrm{X}, \mathrm{Y}$ direction, and the free sliding in $\mathrm{Z}$ direction. The lower end of the mullion constrains the displacement in $\mathrm{X}, \mathrm{Y}$ and $\mathrm{Z}$ directions.

\section{Simulation analysis}

In the way of loading, the vertical load and the horizontal load are explored. Under the vertical load, toughened glass is selected as the wood window glass, with a density of $2500 \mathrm{~kg} / \mathrm{m}^{3}$ and a thickness of $5 \mathrm{~mm}$. The gravity of $1 \mathrm{~m}$ high tempered glass is converted into line load of $0.125 \mathrm{KN} / \mathrm{m}$. The weight of toughened glass of different height can be converted into line load according to the weight of toughened glass of $1 \mathrm{~m}$ height. In the experiment, the weight of glass can be converted into surface load and added to the groove surface of glass and mullion contact. Under the action of horizontal load, when the wind load acts on the wooden window, its stress direction is perpendicular to the plane of the wooden window, and the load-bearing unit composed of the wooden window frame can be regarded as the simply supported plate hinged on four sides. The distribution of wind load can be simplified as trapezoid or triangle. The horizontal wind load is applied to the surface of the mullion and the mullion, and the reduced surface load is applied to the groove where the glass and the mullion contact with the mullion.

\subsection{Research on ultimate bearing capacity}

In the experiment, D10a model is taken as an example, which is loaded vertically first to explore the selection of strength theory and study the stress state. The first principal stress, the second principal stress and the third principal stress at the most dangerous point should be checked, and the strength value according to the Mohr strength theory and the double shear stress strength theory [5]should be calculated, as shown in Table 4. Mohr's strength and double shear strength at different glass heights of D10a model it can be seen from the chart that the calculation results of nodes under Mohr's strength theory are greater than those under double shear strength theory, so we can think that the control strength condition of dangerous points of the model is Mohr's strength theory, so this experiment is based on Mohr's strength theory.

Table 4 Mohr strength and double shear strength of different glass heights of D10a model

\begin{tabular}{|c|c|c|c|c|c|c|}
\hline Glass height $(\mathrm{m})$ & $\begin{array}{l}\text { Line load } \\
(\mathrm{N} / \mathrm{m})\end{array}$ & $\begin{array}{l}\text { First } \\
\text { principal } \\
\text { stresso }_{1} \\
(\mathrm{MPa})\end{array}$ & $\begin{array}{l}\text { Second } \\
\text { principal } \\
\text { stresso } \\
(\mathrm{MPa})\end{array}$ & $\begin{array}{l}\text { Third } \\
\text { principal } \\
\text { stresso }_{1} \\
(\mathrm{MPa})\end{array}$ & $\begin{array}{l}\text { Molar } \\
\text { principal } \\
\text { stresso }_{\mathrm{rM}} \\
(\mathrm{MPa})\end{array}$ & $\begin{array}{l}\text { Double shear } \\
\text { stress strengtho } \\
(\mathrm{MPa})\end{array}$ \\
\hline 0.50 & 62.50 & 2.4891 & 1.5249 & -1.0707 & 3.2029 & 2.2598 \\
\hline 1.00 & 125.00 & 3.6171 & 2.4678 & \begin{tabular}{|l|}
-1.1572 \\
\end{tabular} & 4.3886 & 2.9618 \\
\hline 1.50 & 187.50 & 5.0782 & 3.0877 & $\mid-1.0691$ & 5.7909 & 4.0689 \\
\hline 2.00 & 250.00 & 6.6361 & 3.6064 & -0.99419 & 7.2989 & 5.3300 \\
\hline 2.50 & 312.50 & 8.2164 & 4.13 & -0.93885 & 8.8423 & 6.6208 \\
\hline 3.00 & 375.00 & 9.809 & 4.6793 & -0.92367 & \begin{tabular}{|l|}
10.4248 \\
\end{tabular} & 7.9312 \\
\hline 3.50 & 437.50 & 11.413 & 5.2951 & -0.98935 & 12.0726 & 9.2601 \\
\hline
\end{tabular}

The relationship between Mohr strength of the most dangerous point and glass height of D10a model is shown in Fig.5. In the case of vertical load, through the Mohr strength theory calculation, when the glass height is $3.0 \mathrm{~m}, \sigma_{\mathrm{rM}}=10.4248 \mathrm{MPa}<\left[\sigma_{\mathrm{t}}\right]=12 / 1.1=10.91 \mathrm{MPa}$, when the glass height is $3.5 \mathrm{~m}, \sigma_{\mathrm{rM}}=12.0726 \mathrm{MPa}>\left[\sigma_{\mathrm{t}}\right]$, it can be seen that the ultimate bearing capacity of the model is between $3.0 \sim 3.5 \mathrm{~m}$. Mohr strength increases linearly 
with the increase of glass height, and the more accurate glass height corresponding to the ultimate bearing capacity can be calculated by interpolation as $3.15 \mathrm{~m}$..

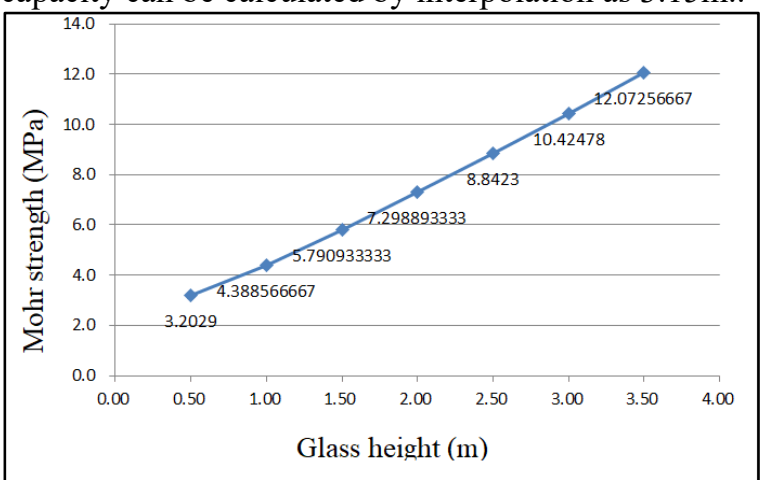

Fig.5.Relationship between Mohr strength of the most dangerous point and glass height of D10a model.

The same experimental method is used to test the components under horizontal load. When different horizontal loads are applied, the stress state and strength checking calculation of dangerous points in D10a model is shown in Fig.6.

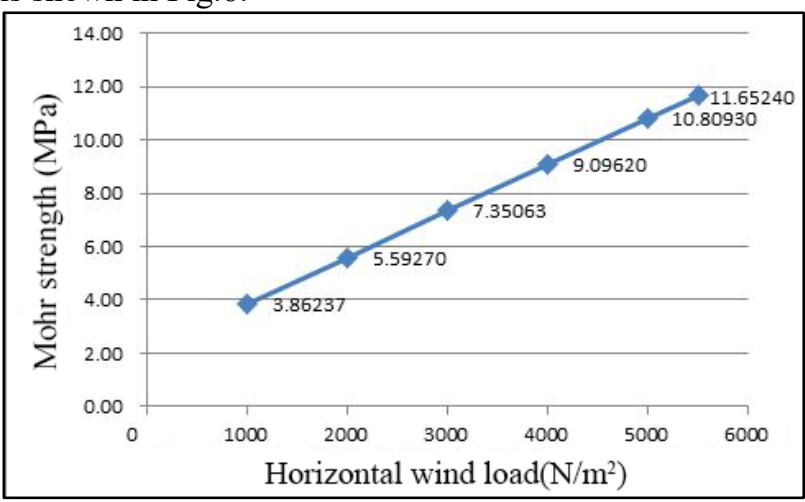

Fig.6.The relationship between the horizontal load on different glass and the Mohr strength at the most dangerous point

\subsection{Displacement value at the contact of model mullion and mullion and in the span}

Under the action of vertical load, it is found that there are cracks in the contact part between the mullion and the mullion. By looking at the displacement nephogram of the contact part of the mullion, it is found that the cracks increase with the increase of load. Through the analysis of specific data, the displacement value under vertical load increases linearly with the increase of load, as shown in Figure 7. The maximum displacement and mid span deflection at the contact part of the cross and mullion are shown in Table 5 .

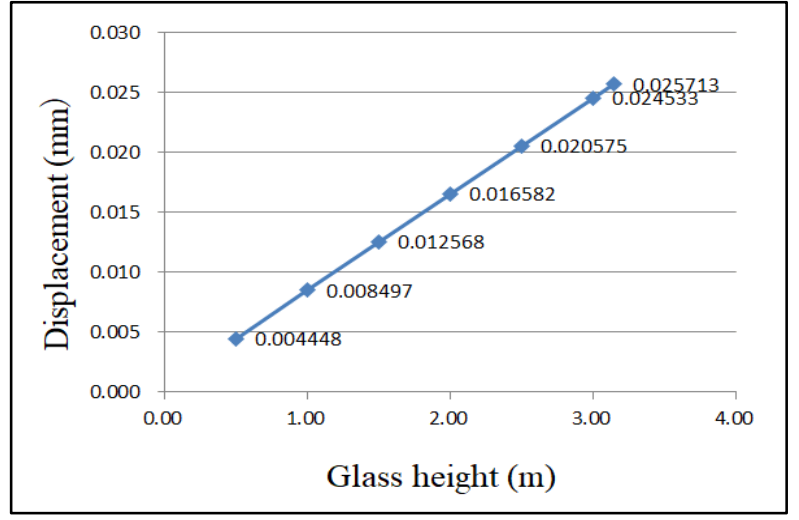

Fig.7.The relationship between the glass height and the maximum displacement in D10a model

Table 5 Displacement value for each model reaching the ultimate bearing capacity

\begin{tabular}{|c|c|c|c|c|c|c|c|c|}
\hline Model number & D7 & D8a & D8b & D9 & D10a & D10b & D12a & D12b \\
\hline Maximum displacement (mm) & 0.0249 & 0.0203 & 0.0336 & 0.0195 & 0.0257 & 0.0267 & 0.0258 & 0.0264 \\
\hline Midspan deflection (mm) & 0.155 & 0.145 & 0.186 & 0.132 & 0.17 & 0.176 & 0.167 & 0.179 \\
\hline
\end{tabular}

When the horizontal load is applied, the failure also occurs at the contact part of cross and mullion. Through specific data analysis, the displacement value increases linearly with the load, as shown in Fig. 8. The maximum displacement and mid span deflection at the contact part of the cross and mullion are shown in Table 6 .

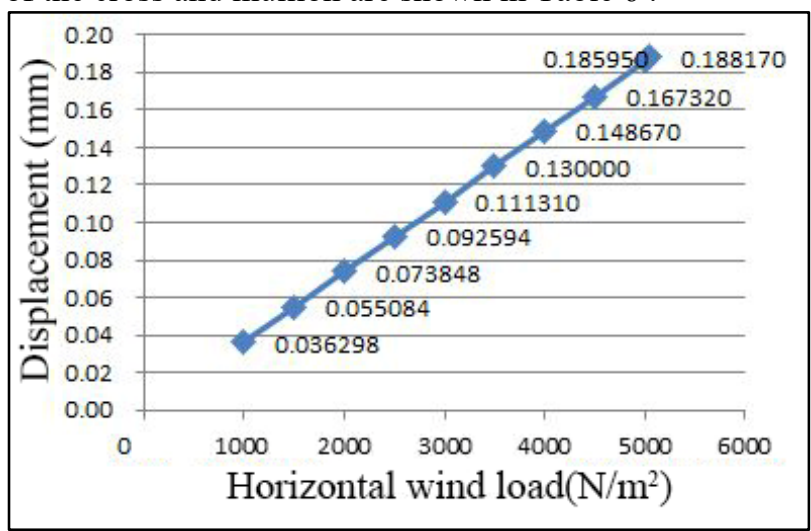

Fig.8 .The relationship between the maximum displacement and the horizontal wind loads on the D10a model

Table 6 Displacement value while each model reaching the ultimate bearing capacity

\begin{tabular}{l|l|l|l|l|l|l|} 
Model number & D7 & D8a & D8b & D9 & D10a & D10b D12a D12b \\
\hline
\end{tabular} \begin{tabular}{|r|r|r|r|r|r|r|r|r|}
\hline Maximum displacement (mm) & 0.1738 & 0.1448 & 0.1395 & 01817 & 0.1882 & 0.1667 & 0.2208 & 0.2356 \\
\hline
\end{tabular}

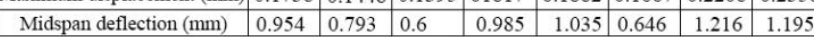

According to the code for design of timber structures [6], the allowable deflection value of this component $[\omega]$ $=\mathrm{L} / 250=765 \mathrm{~mm} / 250=3.06 \mathrm{~mm}$, and the calculated mid span deflection values are less than the allowable deflection values, so it meets the relevant requirements.

According to the code for design of timber structures [6], the allowable deflection value of this component $[\omega]$ $=\mathrm{L} / 250=765 \mathrm{~mm} / 250=3.06 \mathrm{~mm}$, and the calculated mid span deflection values are less than the allowable deflection values, so it meets the relevant requirements.

\subsection{Simulation conclusion analysis}

In the vertical load, compared with five models with tenon length of $60 \mathrm{~mm}$, it is found that the ultimate bearing capacity is larger when the diameter is $10 \mathrm{~mm}$. 
Compared with the model with the diameter of the tenon of $16 \mathrm{~mm}$, it can be seen that the larger the diameter of the tenon, the greater the ultimate bearing capacity. Compared with 6 models with $8,10,12 \mathrm{~mm}$ diameter, it is found that when the diameter of tenon is fixed, increasing the length of tenon will improve the ultimate bearing capacity of the joint, and the model with $8 \mathrm{~mm}$ diameter of tenon will increase the most obviously. Compared with all models, the maximum vertical ultimate bearing capacity is D10b model. The comparison Fig. is shown in Fig. 9 and Fig. 10.

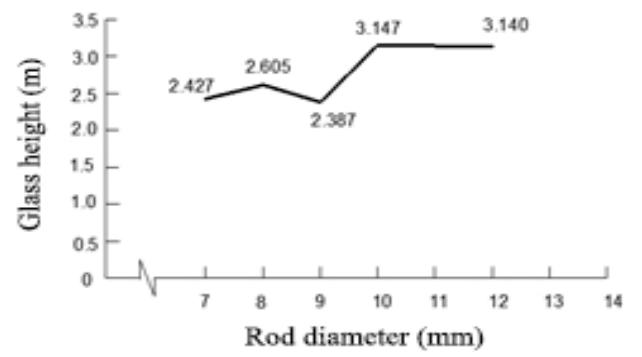

Fig.9. Comparison of height of glass with different tenon

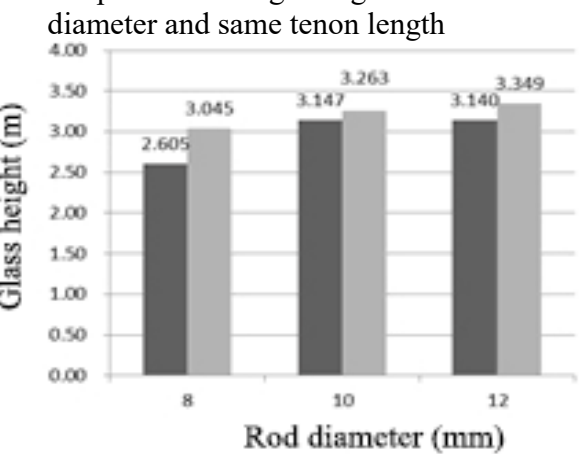

Fig.10. Comparison of glass height with the same tenon diameter and different tenon length

Compared with the five models with a tenon length of $60 \mathrm{~mm}$, it is found that the ultimate bearing capacity is the largest when the tenon diameter is $12 \mathrm{~mm}$. The ultimate bearing capacity tends to increase with the diameter, but it is not that the larger the diameter is, the larger the ultimate bearing capacity is. When the diameter of the tenon is $16 \mathrm{~mm}$ and the horizontal load is $1000 \mathrm{~N} / \mathrm{m}^{2}$, the material has been damaged, and the maximum Mohr strength reaches 13.261mpa. When the length of tenon is increased, it is found that the ultimate bearing capacity of the model with diameter of $8 \mathrm{~mm}$ and $10 \mathrm{~mm}$ is decreased, while that of the model with diameter of $10 \mathrm{~mm}$ is increased. Therefore, the D12b model has the largest ultimate bearing capacity. The comparison Fig. is shown in Fig. 11 and Fig. 12:

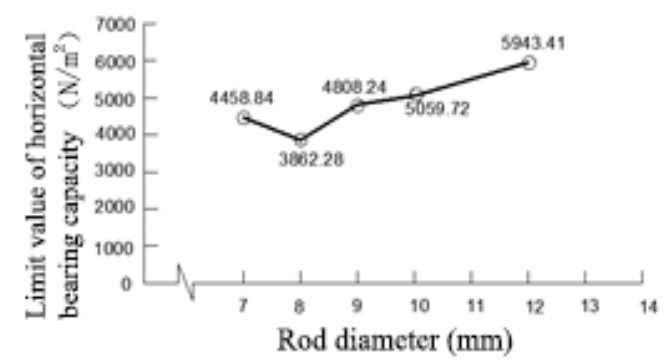

Fig.11. Comparison of ultimate horizontal bearing capacity of different tenons with the same diameter and tenon length

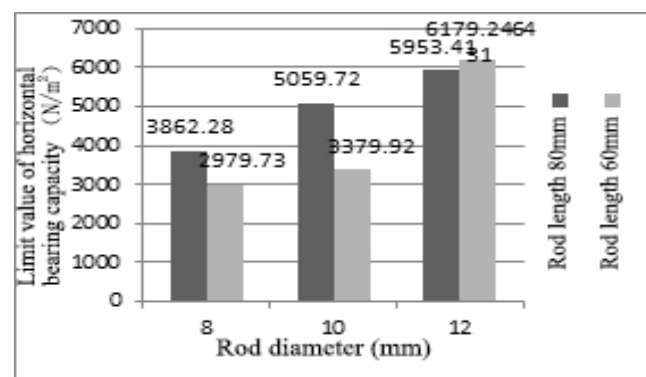

Fig.12. Comparison of ultimate horizontal bearing capacity of different tenon lengths with the same tenon diameter

\section{The conclusion}

Considering the vertical load and the stress-strain situation under the horizontal load, considering the size requirements of the wooden window and the size deviation during the processing, the paper makes a comprehensive comparative analysis of eight models, and draws the following conclusions:

The model with the largest ultimate bearing capacity of this kind of wooden window is the model with a tenon diameter of $10 \mathrm{~mm}$ and a tenon length of $60 \mathrm{~mm}$. Under the vertical load, it can bear a maximum line load of $393.38 \mathrm{~N} / \mathrm{m}$, a maximum displacement value of 0.0257 $\mathrm{mm}$ at the contact part between the crossbeam and the mullion, a maximum wind load of $5059.72 \mathrm{~N} / \mathrm{m}^{2}$ under the horizontal load, and a maximum displacement value of $0.1882 \mathrm{~mm}$ at the contact part between the crossbeam and the mullion.

\section{Acknowledgement}

Supported by Natural Science Foundation of Hebei Province(E2017201158), "one province, one university" special fund, Foundation of Hebei Educational Committee(QN2016171). Innovation and entrepreneurship project of Hebei University.

\section{References}

1. G.F.Wu, Y.Zhong, Y.C.Gong, H.Q.Ren, China wood industry.J. E 33,25 (2019)

2. S.Y.Shen,W.Xu., Art Science and Technology .J The present situation and trend of folding wood furniture with wood cutting structure. Art technology (2019)

3. J.X.Wang, Static and dynamic analysis of mortise mortise joint wood structure .D. (Kunming University of technology, 2008)

4. M.H.Yu, Y.J.Peng, Progress in mechanics.J. century's summary of strength theory (2004)

5. X.F.Sun, X.F.Fang,L.T.Guan, Beijing: Higher Education Press. Materials Mechanics (I)(2010)

6. National standard of the people's Republic of China. Gb50005-2003. Code for design of timber structures.S. (Beijing: China Building Industry Press, 2003) 